\title{
Electrochemical Study of Ion Transfer of Acetylcholine Across the Interface of Water and a Lipid-Modified 1,2-Dichloroethane
}

\author{
Rubin Gulaboski, Carlos M. Pereira,* M. Natália D. S. Cordeiro, ${ }^{\ddagger}$ Ivan Bogeski, ${ }^{\dagger}$ \\ Elisabete Ferreira, David Ribeiro, Mariana Chirea, and A. Fernando Silva \\ Departamento de Quimica, Faculdade de Ciências, Universidade do Porto, 4169-007 Porto, Portugal
}

Received: February 22, 2005; In Final Form: April 7, 2005

\begin{abstract}
The ion transfer of acetylcholine $\left(\mathrm{AcH}^{+}\right)$ions across the unmodified and phospholipid-modified water|1,2dichloroethane (DCE) interface has been studied by means of square-wave and cyclic voltammetry, as well as by electrochemical impedance spectroscopy. After being transferred in the organic phase, the $\mathrm{AcH}^{+}$ions undergo chemical reactions with the phospholipids. The overall behavior of the experimental system studied in the presence of phospholipids has been compared with the theoretical results of an ECrev reaction. The kinetic parameters of the chemical interactions between $\mathrm{AcH}^{+}$and the phospholipids have been determined from the voltammetric and impedance measurements. Additional characterization of those interactions has been made by using the surface tension measurements.
\end{abstract}

\section{Introduction}

The ion transfer across the interface of two immiscible solvents attracts significant attention because of its wide applicability in different fields such as ion-selective electrodes, biomimetic studies of membrane function, drug uptake, and so forth. ${ }^{1-4}$ In the last several decades, it has been proven that the interface between two immiscible electrolyte solutions (ITIES) is suitable for studying the features of charged compounds. ${ }^{1-3}$ The thermodynamics of a large number of organic and inorganic ions, such as the standard Gibbs energy of ion transfer, became feasible to evaluate by applying voltammetric programs at the ITIES in experiments performed with a four-electrode setup..$^{3,5-9}$ Besides, a great number of electrochemical studies at ITIES have been devoted to the determination of the kinetics of ion transfer, ${ }^{10-16}$ as well as to the elucidation of various electrode mechanisms involving the ion and/or electron transfers. ${ }^{17-22}$

The standard Gibbs energy of ion transfer is an important physical parameter which can be deduced from the electrochemical experiments at ITIES, closely related to one of the most important characteristic of the compounds, that is, their lipophilicity. ${ }^{1-4}$ Lipophilicity is a specific property of the compounds which decides to a great extent their distribution, transport, metabolism, toxicity, and thus their biological activity. ${ }^{1,4}$ The common method of assessing the lipophilicity of a compound is to determine its partition coefficient in a system using water as a polar solvent and $n$-octanol as an organic solvent. ${ }^{1,4} n$-Octanol has been chosen as a reference organic solvent in the lipophilicity measurements because of its similarities with the phospholipids, which are the major constituents of the biological membranes. Although $n$-octanol has been used for predicting the partition coefficients of a large number of neutral compounds, ${ }^{4}$ only recently has an electrochemical method, based on a three-phase electrode, been developed for determining the partition coefficients of ions across the water $n$ octanol interface. ${ }^{23,24}$ The recently developed three-phase electrode technique has proven to be a powerful tool for measuring

* E-mail: cmpereir@fc.up.pt.

Department of Physiology, University of Saarland, Homburg, Germany. $\div$ REQUIMTE the thermodynamics of the ion transfer across various liquid|liquid interfaces, ${ }^{22-28}$ as well as for investigating interfacial redox mechanisms. ${ }^{27-30}$ Since the interface of water $\mid n$-octanol still remains nonpolarizable with the classical four-electrode voltammetric techniques at ITIES, in order to get a closer insight into the ion transfer mechanisms occurring in the living species, alternative solvents for $n$-octanol are used. Dichloroethane (DCE) is particularly well suited for such studies., ${ }^{1,2,4}$ Because of the low permittivity of 1,2-dichloroethane, the properties of the interface between the water and the DCE have some similarities with the interface between the biological membranes and water. ${ }^{1,4,31}$ Furthermore, very often, the ITIES is being modified with various lipids. ${ }^{1,4,10,11,32-35}$ In this way, the ITIES mimics closely the biomembranes, ${ }^{1,4}$ and reliable information about the processes taking place in the living organisms can be obtained.

In this paper, we present a comprehensive set of experiments for studying the transfer of acetylcholine cations across the interface of water and DCE modified by phosphatidylcholine. This lipid has been chosen since it is well-known that the phosphatidylcholines are the major constituents of cell membranes. ${ }^{1,4}$ Phospholipids consist of a water-soluble head (a positively charged, polar group), linked to two water-insoluble nonpolar tails (by a negatively charged phosphate group). Both tails consist of a fatty acid, each 14-24 carbon groups long. Because of its polar nature, the head of phospholipids is attracted to water (it is hydrophilic), while the nonpolar tail is repelled from the water, since it is hydrophobic. When placed in water, phospholipids can form a bilayer, where the hydrophobic tails line up against each other forming a membrane with hydrophilic heads on both sides. This membrane is partially permeable and very flexible. ${ }^{4}$ The adsorption of the phospholipids at the water|organic solvents interfaces are thoroughly studied by several groups, and detailed information can be found elsewhere. ${ }^{34,35}$ Furthermore, phosphatidylcholines are also the major delivery form of the essential nutrient choline. Choline itself is a precursor in the synthesis of the neurotransmitter acetylcholine. The chemical compound acetylcholine, often abbreviated as $\mathrm{AcH}^{+}$, was the first neurotransmitter to be identified. It is a 
chemical transmitter in the central nervous system (CNS) as well as in the parasympathetic nervous system in many organisms including humans. Acetylcholine is also active in the brain, where it tends to cause excitatory actions. Accordingly, it plays an important role in the metabolisms of all living organisms. A study of the transfer of $\mathrm{AcH}^{+}$across the water|nitrobenzene and water|DCE interface is referred elsewhere. ${ }^{36-38}$ Our aim with this study is to mimic the transfer of acetylcholine across the lipid films in order to get more reliable information about its features during the transfer across the membranes in the living organisms. For this purpose, we performed voltammetric and impedance experiments at ITIES, as well as surface tension measurements, in turn to clarify the ion transfer process of acetylcholine and to refer the possible interactions between the acetylcholine and the phospholipids.

\section{Experimental Section}

All the chemicals, 1,2-dichloroethane (99.9\%, Sigma), chloroform (Riedel-de Haën, Chromasolv, 99.8\%), lithium chloride (Aldrich, 99\%), acetylcholine chloride (Aldrich, 98\%), dioleoylphosphatidylcholine (DOPC) (Lipid Products, Surrey, U.K.), tetraoctylammonium tetraphenylborate (TOATPB), and sodium tetraphenylborate (NaTPB), were used as received. Mili Q-plus water $(18 \mathrm{M} \Omega \mathrm{cm}$ ) was used for preparation of all aqueous solutions, as well as for rinsing. Acetylcholine tetrakis(tetrachlorophenyl)borate (used for the organic phase) was prepared by metathesis from the aqueous solution of acetylcholine chloride and the methanol solution of potassium tetrakis(tetrachlorophenyl)borate (Fluka, 99\%). All experiments were carried out at room temperature. For the electrochemical measurements, the following four-electrode cell, with a flat water|DCE interface having an area of $0.28 \mathrm{~cm}^{2}$, was used:

$$
\begin{aligned}
& \mathrm{Ag} / \mathrm{AgCl} \mid 10 \mathrm{mM} \mathrm{NaTPB}+ \\
& 10 \mathrm{mM} \mathrm{LiCl}(\mathrm{w}) \mid 10 \mathrm{mM} \text { TOATPB + } \\
& x \mathrm{mM} \mathrm{AcH}^{+}(\mathrm{DCE}) \mid y \mathrm{mM} \mathrm{AcH}{ }^{+}+ \\
& 0.1 \mathrm{M} \mathrm{LiCl}(\mathrm{w}) \mid \mathrm{Ag} / \mathrm{AgCl}
\end{aligned}
$$

The voltammetric measurements at ITIES were carried out by applying both cyclic staircase (CV) and square-wave voltammetry (SWV). All voltammograms have been measured by compensating the ohmic drop. Impedance spectra have been performed by using FRA Solartron Model 1250, Solartrons Instruments, U.K. In the impedance measurements, a sinusoidal potential signal with an amplitude of $20 \mathrm{mV}$ has been applied at ITIES. The frequency has been varied from 200 to $0.5 \mathrm{~Hz}$, which is typical for these kind of experiments. ${ }^{9-13}$ The equilibration time before applying the measuring program was set to $3600 \mathrm{~s}$ in order to allow the lipid adsorption at the water|DCE interface. The description of the impedance measuring program can be found in a previous work. ${ }^{39}$ In all impedance measurements, equimolar concentrations of $\mathrm{AcH}^{+}$in both the aqueous and organic phases have been used. The measured and simulated impedance spectra were analyzed with the help of EQUIVCRT software.

For the surface tension measurements, a computer-controlled Langmuir trough (KSV Instruments, Ltd., Helsinki) with 364 $\mathrm{mm}$ (length) by $75 \mathrm{~mm}$ (width) was used. The trough was thermostated at $20.0 \pm 0.2{ }^{\circ} \mathrm{C}$ with a Julabo F12-MV bath. The lipid solutions were spread onto the subphase with an SGE gastight syringe. After allowing $30 \mathrm{~min}$ for solvent evaporation, the isotherm were recorded with a compression rate of $5 \mathrm{~mm}$ $\min ^{-1}$.
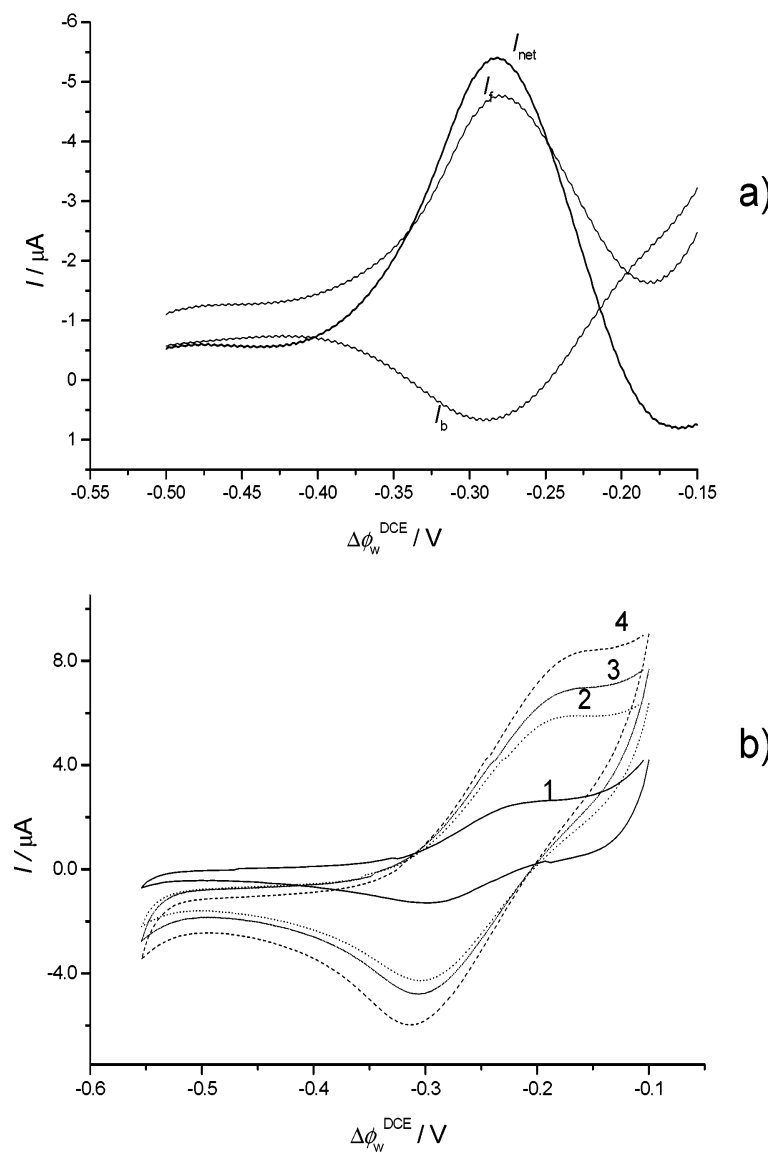

Figure 1. Square-wave (a) and cyclic (b) voltammograms showing the transfer of $\mathrm{AcH}^{+}$across the water|DCE interface. The experimental conditions were as follows: SW frequency $f=8 \mathrm{~Hz}$, potential increment $\mathrm{d} E=1 \mathrm{mV}$, SW amplitude $E_{\mathrm{sw}}=50 \mathrm{mV}$, starting potential $E_{\mathrm{s}}=$ $-0.150 \mathrm{~V}$ (for a) and scan rate $v / \mathrm{mV} \mathrm{s}^{-1}=10$ (1), 25 (2), 50 (3), and 75 (4), and starting potential $E_{\mathrm{s}}=-0.100 \mathrm{~V}$ (for b). $c\left(\mathrm{AcH}^{+}\right)_{\mathrm{w}}=0.2$ $\mathrm{mM}$. Here and in all other figures where they appear, the subscripts "net", "f", and "b" stand for the net, forward, and backward components of the current, respectively.

\section{III.Voltammetric Experiments}

A. Voltammetric Features of the Ion Transfer of Acetylcholine across Unmodified Water|DCE Interface. The squarewave and cyclic voltammograms portraying the transfer of acetylcholine cations $\left(\mathrm{AcH}^{+}\right)$across the water|DCE interface are presented in Figure $1 \mathrm{a}$ and $\mathrm{b}$, respectively. The negative currents of both square-wave and cyclic voltammograms correspond to the transfer of $\mathrm{AcH}^{+}$ions from the water to DCE, while the positive currents correspond to the transfer of $\mathrm{AcH}^{+}$ from DCE to the water. The potential separation between the cathodic and anodic peaks in the cyclic voltammogram for a scan rate of $10 \mathrm{mV} / \mathrm{s}$ reads $65 \mathrm{mV}$, which is close to the theoretical value of $59 \mathrm{mV}$, characteristic for reversible electrochemical behavior. The ratio between the forward and backward peak currents of the square-wave voltammograms reads 1.15 for a frequency of $8 \mathrm{~Hz}$. Being dependent on the concentration of $\mathrm{AcH}^{+}$in the aqueous phase, the peak currents of both peaks of the cyclic voltammograms increase linearly by $c\left(\mathrm{AcH}^{+}\right)$in the range of 0.1 to $2 \mathrm{mM}$. The peak currents of both cathodic and anodic peaks of the cyclic voltammograms are proportional to the square root of the scan rate in the range between 2 and $150 \mathrm{mV} \mathrm{s}^{-1}$ or to the square root of the SW frequency in the region between 8 and $75 \mathrm{~Hz}$ (not shown). This behavior shows that diffusion is the major method of mass transfer of the $\mathrm{AcH}^{+}$cations. The slopes of the dependences $I_{\mathrm{p}}-v^{0.5}$ were used to determine the diffusion coefficient of $\mathrm{AcH}^{+}$ 

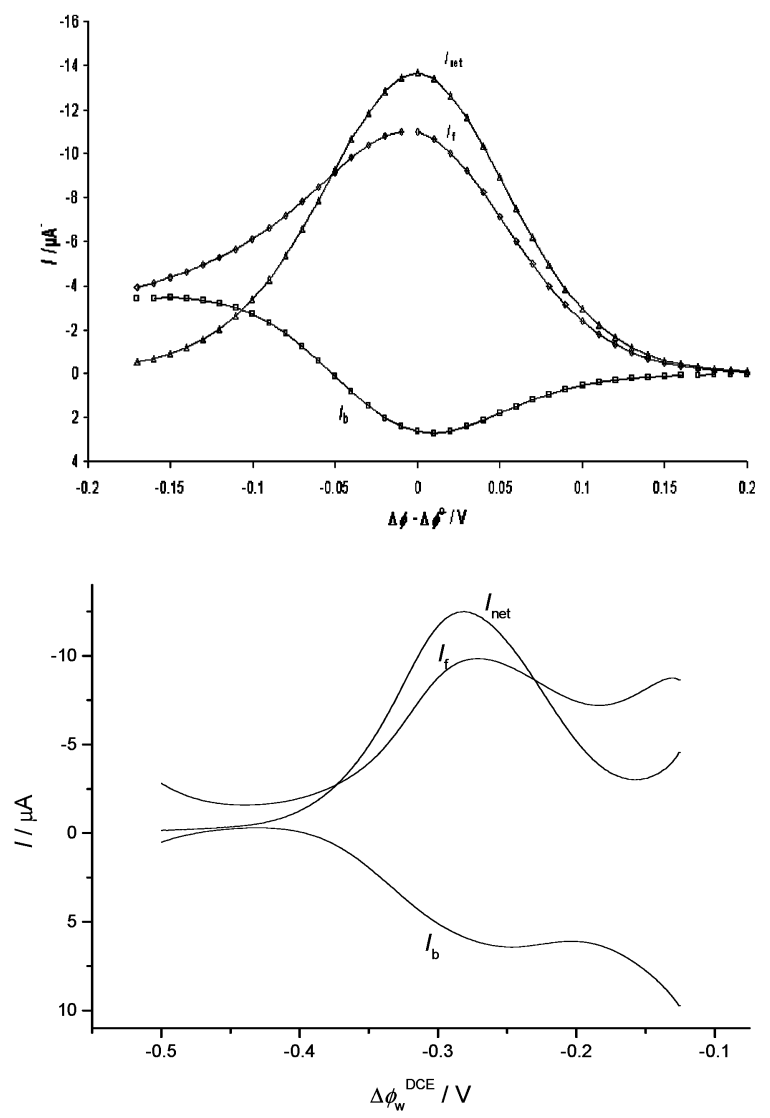

b)

Figure 2. Comparison between the theoretical (a) and experimental (b) voltammograms of the transfer of $\mathrm{AcH}^{+}$across the water|DCE interface. The experimental conditions of the voltammogram (b) are those given in Figure 1a, while $c\left(\mathrm{AcH}^{+}\right)_{\mathrm{w}}=0.5 \mathrm{mM}$. The theoretical voltammogram has been simulated for the same conditions as in the experiment, $T=298 \mathrm{~K}$, standard rate constant of ion transfer $k_{\mathrm{s}}=$ $0.003 \mathrm{~cm} \mathrm{~s}^{-1}$, and ion transfer coefficient $\alpha=0.5$.

in water, which reads $D\left(\mathrm{AcH}^{+}\right)_{\mathrm{w}}=4.0 \times 10^{-6} \mathrm{~cm}^{2} \mathrm{~s}^{-1}$. In an equivalent manner, initially having $\mathrm{AcH}^{+}$in the organic phase only, the diffusion coefficient of $\mathrm{AcH}^{+}$in DCE was determined to be $D\left(\mathrm{AcH}^{+}\right)_{\mathrm{DCE}}=9.5 \times 10^{-7} \mathrm{~cm}^{2} \mathrm{~s}^{-1}$. These values are almost identical to those determined previously by Shao and Girault. ${ }^{38}$ An alteration of the scan rate from 10 to $100 \mathrm{mV} \mathrm{s}^{-1}$ is followed by an increase of the potential separation between the cathodic and anodic peaks from 65 to $100 \mathrm{mV}$. This fact implies that in this range of scan rates the ion transfer of $\mathrm{AcH}^{+}$ across the interface water|DCE is a kinetically controlled process. To evaluate the standard rate constant of $\mathrm{AcH}^{+}$across the water|DCE interface, we have used a fitting of the experimental square-wave and cyclic voltammograms to the theoretical voltammograms obtained by assuming semi-infinite diffusion at a planar electrode (see Appendix 1). By exploiting the identical experimental parameters in the theoretical model, the best fitting has been obtained for a value of the standard rate constant of ion transfer of $k_{\mathrm{s}}\left(\mathrm{AcH}^{+}\right)=3.0 \times 10^{-3} \mathrm{~cm} \mathrm{~s}^{-1}$ (see Figure $2 \mathrm{a}$ ). The fitting procedure relies on the comparison of the theoretical and experimental potential separation between the cathodic and anodic current components, as well as on comparison of their peak current ratio. Noting that, in the mathematical model, the value of the ion transfer coefficient of $\alpha=0.5$ has been used. It is worth noting that the value of the standard rate constant of acetylcholine ion transfer is close to that determined by chronoculometry. ${ }^{38}$

B. Voltammetric Features of the Ion Transfer of Acetylcholine Across Phospholipid-Modified Water|DCE Interface. The modification of the interface between the water and the
DCE, by addition of DOPC in the latter solvent, leads to evident changes in the ion transfer voltammetric behavior of $\mathrm{AcH}^{+}$. Shown in Figure $3 \mathrm{a}-\mathrm{c}$ are SWVs of the transfer of $\mathrm{AcH}^{+}$across the liquid|liquid interface which is modified with various amounts of DOPC in the organic phase. For a constant concentration of $\mathrm{AcH}^{+}$in the water phase, the increase of the concentration of DOPC in DCE is reflected by diminishing the backward component of the currents of the square-wave voltammograms. Similarly, for a constant concentration of DOPC in the organic phase, the increase of the concentration of $\mathrm{AcH}^{+}$in the aqueous phase leads again to a decrease of the backward currents of the SWVs (see Figure $3 \mathrm{a}^{\prime}-\mathrm{c}^{\prime}$ ). In addition, both an increase of the concentration of $\mathrm{AcH}^{+}$in the aqueous phase and an increase of the concentration of DOPC in the organic phase are followed by shifting of the formal potentials of the SWVs toward more negative values. The measured SW peak potentials are sigmoidal functions of the logarithm of the square root of $c$ (DOPC) in the organic phase, with a well-defined linear part. It is worth noting that an increase of the SW frequency of the exciting signal, for a given concentration of $\mathrm{AcH}^{+}(\mathrm{w})$ and DOPC(DCE), also leads to the same phenomena as those described by increasing the concentrations of $\mathrm{AcH}^{+}$(w) and DOPC(DCE).

The influence of the concentration of DOPC on the CVs of the transfer of $\mathrm{AcH}^{+}$is presented in Figure 4. An increase of the concentration of DOPC is followed by a widening of the potential separation between the cathodic and anodic peaks, and additionally by a diminishing of the current of the peak at more positive potentials. Identical effects to the CVs have also been observed by increasing the concentration of $\mathrm{AcH}^{+}$in the aqueous phase, for a constant concentration of the DOPC in the organic phase, and by increasing the scan rate, for constant concentrations of $\mathrm{AcH}^{+}$(w) and DOPC(DCE) (not shown).

The above-described voltammetric features of $\mathrm{AcH}^{+}$, in the presence of DOPC in the organic phase, are typical for the electrochemical systems that are coupled by following chemical reaction (i.e., for the ECrev reactions ${ }^{40,41}$ ). Clearly, the ions of $\mathrm{AcH}^{+}$, after being transferred in the organic phase, can interact with the DOPC molecules, creating a complex. The overall reaction can be presented by the following scheme:

$$
\begin{gathered}
\mathrm{AcH}^{+}(\mathrm{w}) \rightleftarrows \mathrm{AcH}^{+}(\mathrm{DCE})+\operatorname{DOPC}(\mathrm{DCE}) \underset{k_{\mathrm{b}}}{\stackrel{k_{\mathrm{f}}}{\rightleftarrows}} \\
\mathrm{AcH}-\mathrm{DOPC}(\mathrm{DCE})
\end{gathered}
$$

Keeping in mind the fact that the DOPC molecules are charged, containing positive and negative charge at the polar head, it is plausible to assume that the negative side of the DOPC polar head is the possible site involved in the chemical interactions with the $\mathrm{AcH}^{+}$ions. All these effects observed upon the ion transfer of $\mathrm{AcH}^{+}$after the modification of the liquid|liquid interface comply very well with the theoretical results obtained by considering an ECrev reaction (see simulated square-wave and cyclic voltammograms on Figure 5). This is a very important finding, since it shows that the transfer of $\mathrm{AcH}^{+}$across the phospholipid-modified interfaces is not just a simple one. It can be formally classified into the group of chemically assisted ion transfer processes. ${ }^{1,4}$ The statement that the phospholipids can serve as ionophores is described in detail elsewhere. ${ }^{34,35}$ The additional characterizations of the ion transfer process of $\mathrm{AcH}^{+}$ across unmodified and modified water|DCE interface have been made by means of electrochemical impedance spectroscopy (EIS). It is worth mentioning here that the alteration of the $\mathrm{pH}$ 


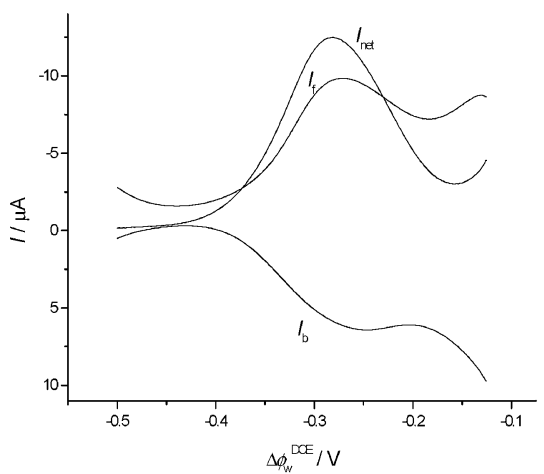

a)

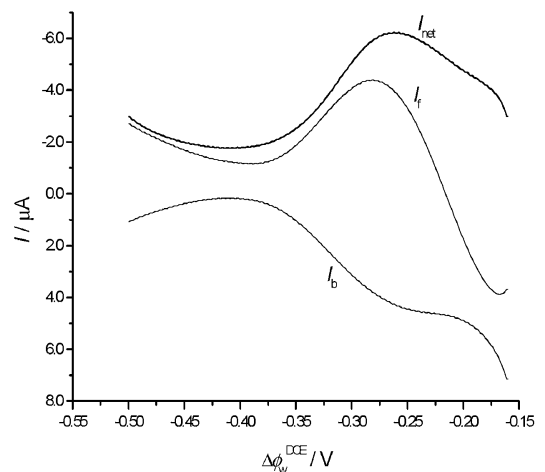

$\left.a^{\prime}\right)$

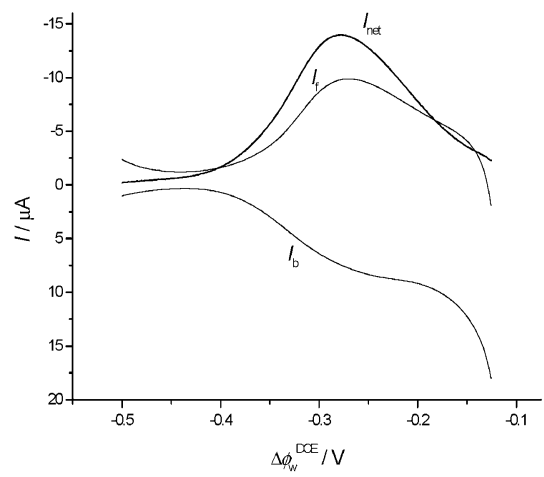

b)
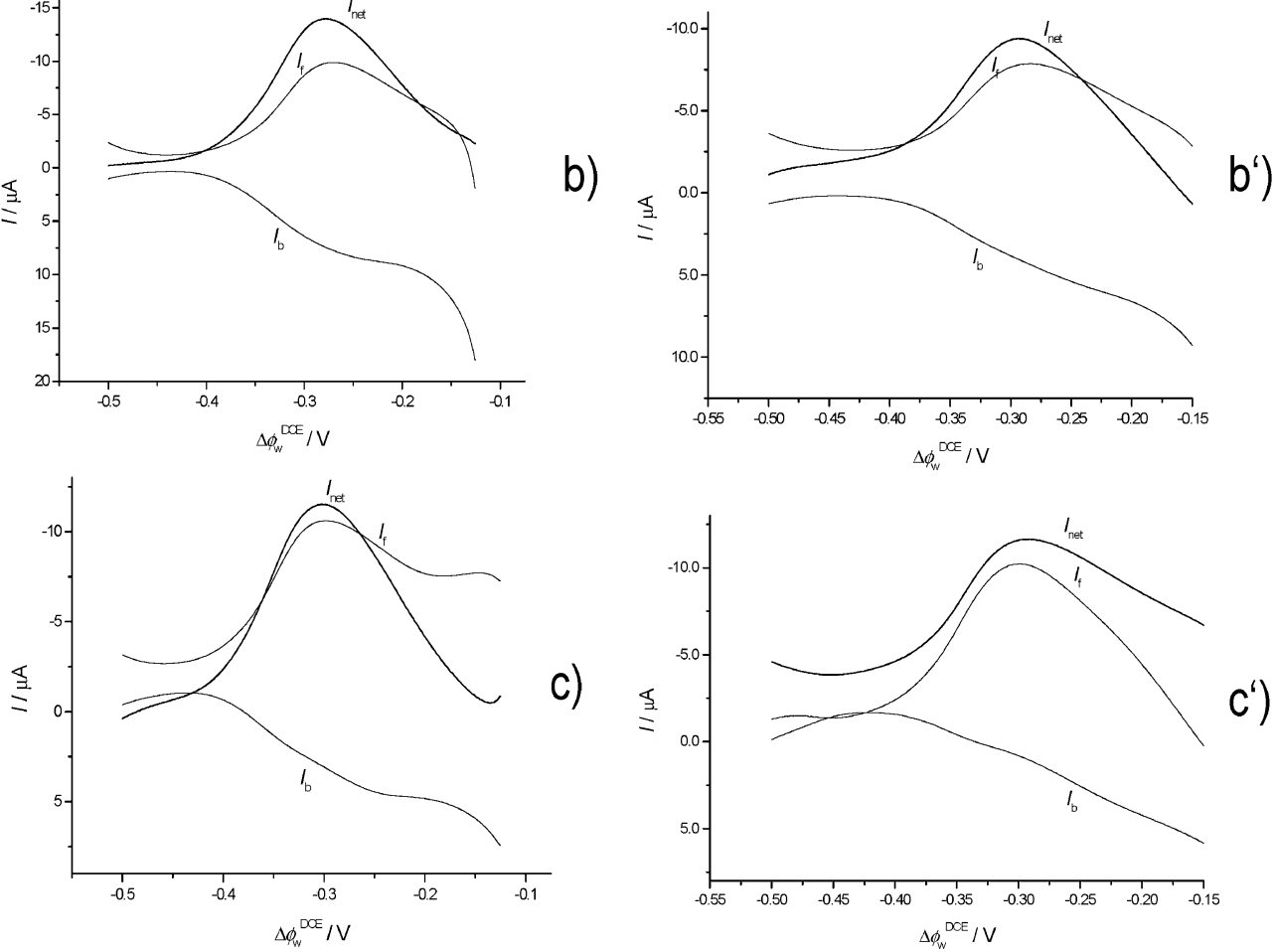

Figure 3. Square-wave voltammograms showing the effect of the DOPC to the shape of the SW current components. The concentration of DOPC

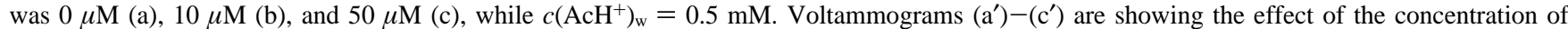
$\mathrm{AcH}^{+}$to the SW current components, in the presence of $30 \mu \mathrm{M}$ DOPC in the organic phase. $c\left(\mathrm{AcH}^{+}\right)_{\mathrm{w}} / \mathrm{mM}=0.2\left(\mathrm{a}^{\prime}\right), 0.5\left(\mathrm{~b}^{\prime}\right)$, and $0.75\left(\mathrm{c}^{\prime}\right)$. The other conditions are the same as those in Figure 1a.

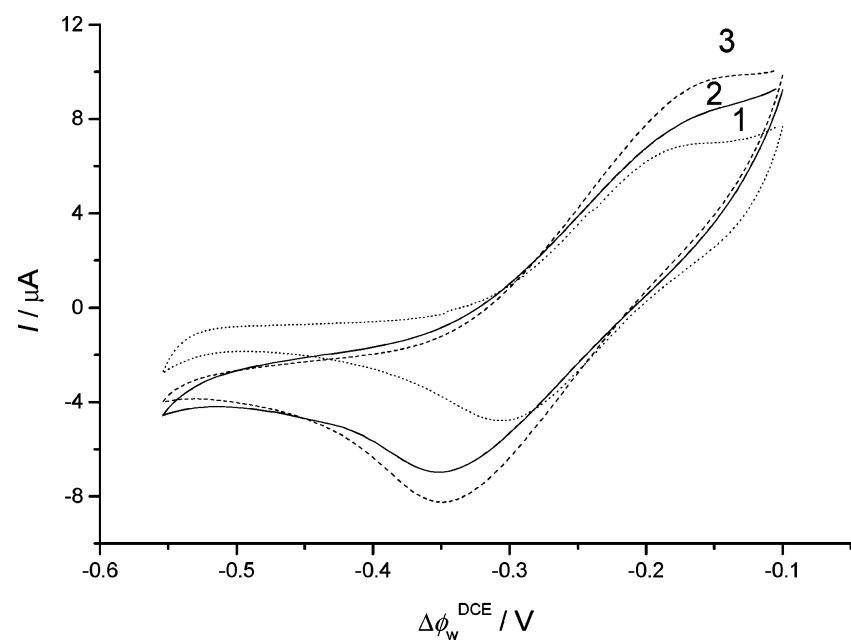

Figure 4. The effect of the DOPC to the cyclic voltammograms of the ion transfer of $\mathrm{AcH}^{+}$recorded at scan rate of $v=50 \mathrm{mV} \mathrm{s}^{-1}$. $c\left(\mathrm{AcH}^{+}\right)_{\mathrm{w}}=0.5 \mathrm{mM}$, while $c(\mathrm{DOPC}) / \mu \mathrm{M}=0$ (1), $30(2)$, and $50(3)$.

of the aqueous electrolytes from 2 to 10 does not provoke any significant changes in the voltammetric behavior.

\section{Impedance Measurements of $\mathrm{AcH}^{+}$Transfer Across the Water|DCE Interface}

It has been proven in many studies that EIS is a suitable technique for studying the electrochemical mechanisms at ITIES, as well as for measuring their kinetics. ${ }^{1,9-13}$ It is possible to derive impedance as a function of the kinetic parameters for a given mechanism; however, a more usual procedure is to fit the data to an equivalent circuit and then interpret the significance of the capacitors, resistors, or other elements either by guess-test or by preferably using a theory to extract kinetic parameters. Usually, one initially makes the so-called measurement-modeling (e.g., fitting the experimental data to an equivalent circuit) and then process-modeling (i.e., extracting the kinetic parameters). ${ }^{42-45}$ In any case, the EIS coupled with the voltammetric technique is a powerful toll for both kinetic measurements and characterization of electrode mechanisms.

Shown in Figure 6 are typical impedance plots recorded at ITIES in the system without $\mathrm{AcH}^{+}$(curve 1) and with $\mathrm{AcH}^{+}$ present in equimolar concentrations in both the water and DCE phases (curve 2). In the low-frequency region of curve 2 (i.e., 

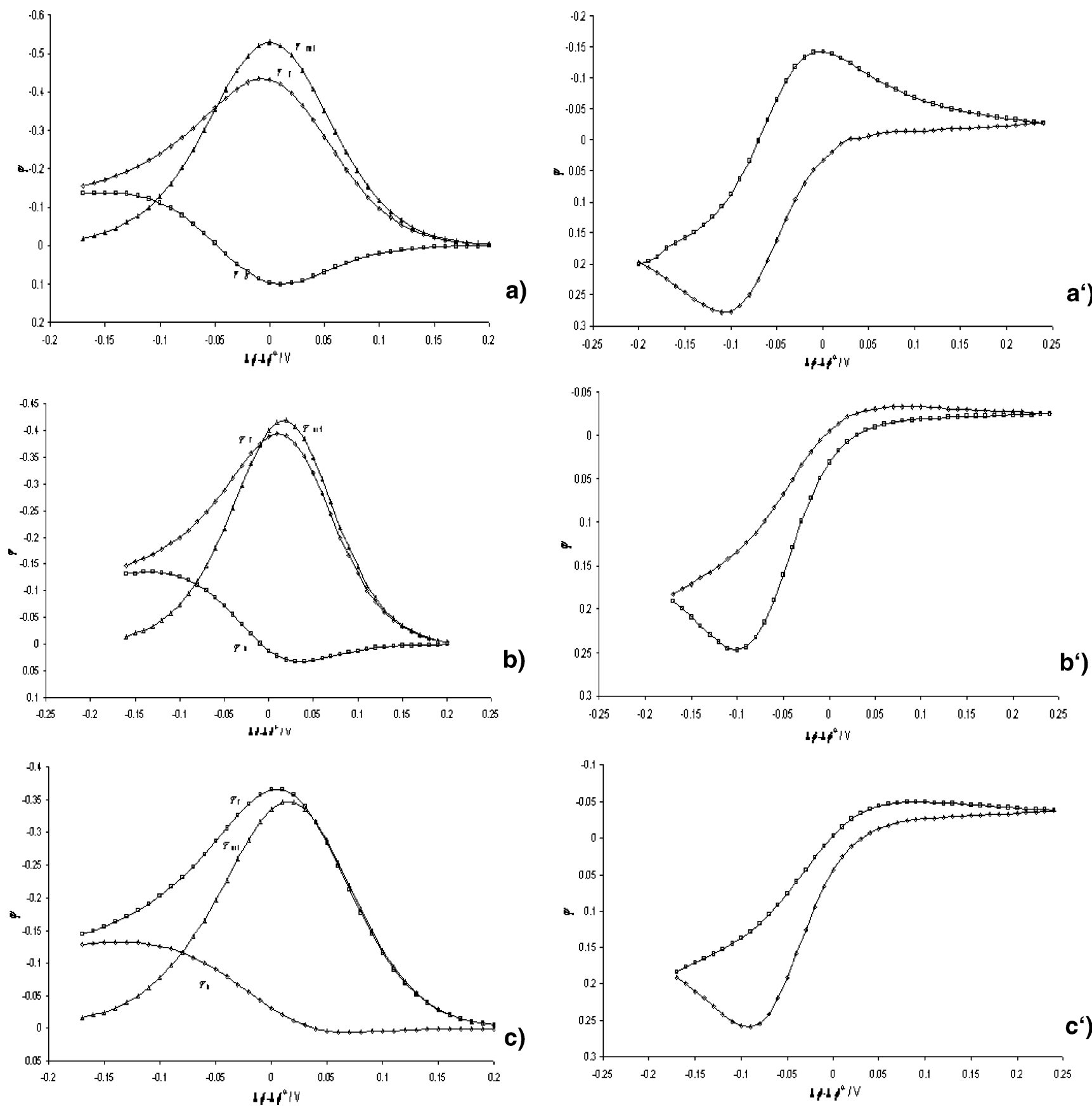

Figure 5. The effect of the chemical parameter $z$ to the shape of the theoretical SW $(a-c)$ and cyclic $\left(a^{\prime}-c^{\prime}\right)$ voltammograms simulated by considering an ECrev reaction. $z=0.158$ ( $\mathrm{a}$ and $\left.\mathrm{a}^{\prime}\right), 0.748\left(\mathrm{~b}\right.$ and $\left.\mathrm{b}^{\prime}\right)$, and $1.256\left(\mathrm{c}\right.$ and $\left.\mathrm{c}^{\prime}\right)$. The other simulation parameters were as follows: $k_{\mathrm{s}}$ $=0.003 \mathrm{~cm} \mathrm{~s}^{-1}, K=0.1$, and $\alpha=0.5$ (for all SW and cyclic voltammograms). Figures (a) - (c) are simulated for SW frequency $f=8 \mathrm{~Hz}, \mathrm{SW}$ amplitude $E_{\mathrm{sw}}=50 \mathrm{mV}$, and $\mathrm{d} E=4 \mathrm{mV}$, while the cyclic voltammograms $\left(\mathrm{a}^{\prime}-\mathrm{c}^{\prime}\right)$ are simulated for a scan rate of $v=8 \mathrm{mV} \mathrm{s}{ }^{-1}$. The currents are normalized as $\Psi=I /\left(F S D^{0.5} f^{0.5} c^{*}\right)$ (for SW) and $\Psi=I \tau^{0.5} /\left(F S D^{0.5} c^{*}\right)$ (for $\mathrm{CV}$ ).

for frequencies lower than $12 \mathrm{~Hz}$ ), the mass transfer dominates, and the unit slope between the imaginary part $Z^{\prime \prime}$ and the real part $Z^{\prime}$ of the impedance is observed. Above the frequencies of $12 \mathrm{~Hz}$, there is a limited-frequency kinetic region, where the major contribution to the impedance comes from the kinetics of the ion transfer reaction. This is the semicircle region of curve 2 in Figure 6. At very high frequencies, the impedance plot of $\mathrm{AcH}^{+}$merges with that of the supporting electrolyte, which is determined by the solution resistance. Both the real and imaginary parts of the impedance are linear functions of the square root of the inverse frequency in the low-frequency region, having identical slopes equal to the Warburg coefficient $\sigma$, as is typical for diffusion-controlled reactions (not shown).
The transfer of $\mathrm{AcH}^{+}$across the ITIES can be represented by the Randles equivalent circuit consisting of a parallel combination of the interfacial capacitance and the faradaic impedance, in series with the resistor representing the solution resistance. The faradaic impedance is represented by a resistor element (i.e., the resistance due to the charge transfer at ITIES) in series with the Warburg impedance element, which represents the resistance owing to the mass transfer.

The plots of the Warburg impedance and charge transfer resistance are parabolic functions of the applied potential across the liquid|liquid interfaces with maxima located nearby the formal potential of the ion transfer of $\mathrm{AcH}^{+}$. Shown in the Figure 7 is the dependence of the logarithm of the apparent ion 


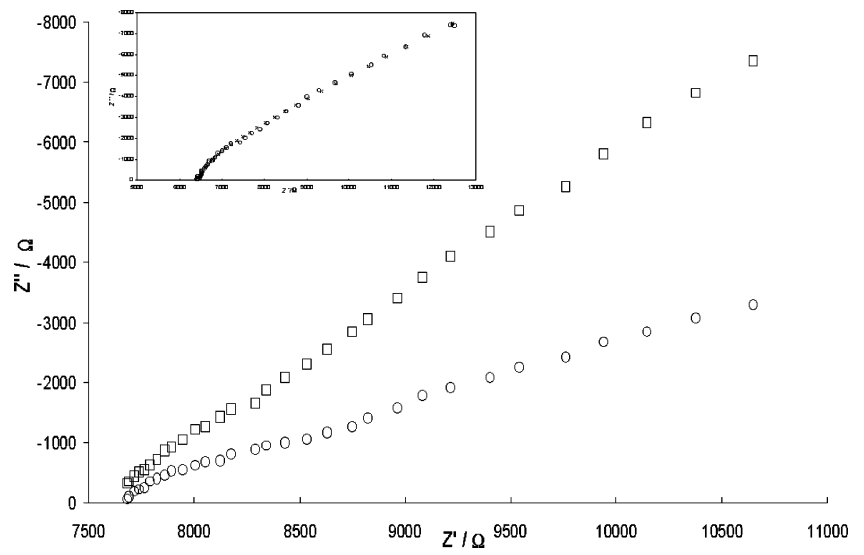

Figure 6. Nyquist impedance plots for the base electrolytes in water and DCE (curve 1) and for the $0.5 \mathrm{mM} \mathrm{AcH}^{+}$present in both water and DCE (curve 2) recorded at equilibrium potential. In the inset is shown the fitting between the experimental data of $\mathrm{AcH}^{+}$ion transfer and theoretical data obtained by considering the Rundles equivalent circuit.

transfer constants of $\mathrm{AcH}^{+}$, evaluated from the charge transfer resistances, on the applied potential difference at the liquid|liquid interface. At potentials more negative and more positive than the formal potential of transfer of $\mathrm{AcH}^{+}$, the apparent rate constants rise exponentially with the applied potential difference. The spot where both lines of Figure 7 cross each other corresponds to the value of the standard rate constant of ion transfer of $\mathrm{AcH}^{+}$, which is estimated to be $k_{\mathrm{s}}=3.3 \times 10^{-3} \mathrm{~cm}$ $\mathrm{s}^{-1}$. For estimating the $k_{\mathrm{s}}$, we have used the common relationship between the charge transfer resistance $R_{\mathrm{ct}}$ and the exchanging current $I_{\mathrm{o}}$, that is, $R_{\mathrm{ct}}=R T /\left(F I_{\mathrm{o}}\right)$, where $I_{\mathrm{o}}$ is given by $I_{\mathrm{o}}=$ $z F S c^{*} k_{\mathrm{s}} . c^{*}$ is the initial concentration of the $\mathrm{AcH}^{+}$, while other symbols have their usual meaning. Note that the charge transfer resistance has been determined with an error less than $10 \%$, so the accuracy of the estimated value of the standard rate constant is higher than $90 \%$. This value of $k_{\mathrm{s}}$ is in very good agreement with the value estimated by fitting the experimental and theoretical voltammograms. The slopes of the linear parts presented on Figure 7 are linked to the ion transfer coefficient with the relation $\mathrm{d} \ln \left(k_{\mathrm{s}}\right) / \mathrm{d} E=\alpha F / R T$. The estimated value of the cathodic ion transfer coefficient from the slope reads $\alpha=$ 0.53 . This value is identical to those reported by Shao and Girault. ${ }^{38}$

\section{Impedance Measurements of $\mathrm{AcH}^{+}$Transfer Across the Phospholipid-Modified Water|DCE Interface}

The impedance plot of $Z^{\prime \prime}$ versus $Z^{\prime}$ of the studied system, recorded in the presence of DOPC in the organic phase, is given in Figure 8. Similarly to the situation without DOPC in the organic phase, there is a linear dependence between $Z^{\prime \prime}$ and $Z^{\prime}$ within a lower frequency range, with slope of 1 (not shown). Again, in the lower frequency region, both the real $Z^{\prime}$ and imaginary $Z^{\prime \prime}$ parts of the impedance are linear functions of the inverse square root of the frequency, having identical slopes. The figure shows that the semicircle diameter in the presence of DOPC in the organic phase (curve 2) is smaller than the same semicircle in the absence of DOPC. This effect arises from the decrease in the apparent resistance of the charge transfer as a consequence of the following chemical reaction, which is in accordance with the theoretical findings described by Canas et al. ${ }^{42}$ The effect of the following chemical reaction to the impedance data can be also recognized from the curves presented in Figure 9a,b. An increase of the concentration of DOPC in the organic phase, for a constant $\mathrm{AcH}^{+}$concentration ratio in both phases, is portrayed by a shift of the maxima of both the charge transfer resistance $R_{\mathrm{ct}}$ and the Warburg (mass transfer) impedance $W$ toward more negative potentials. Similar shifts of the maxima of $R_{\mathrm{ct}}$ and $Z_{\mathrm{w}}$ have also been observed by changing the concentration ratio of $\mathrm{AcH}^{+}$, for a constant concentration of DOPC in the organic phase (not shown). Moreover, the maxima of both the charge transfer resistance and the Warburg resistance are slightly diminished by increasing the concentration of DOPC, which is a consequence of the decrease in the apparent resistance due to the coupled following chemical reaction. ${ }^{42}$ All these features have been also predicted in the theoretical impedance analysis of an ECrev reaction made by Smith and Sluyters et al. ${ }^{43 a-c}$ Note that the impedance behavior of the studied system in the presence of DOPC

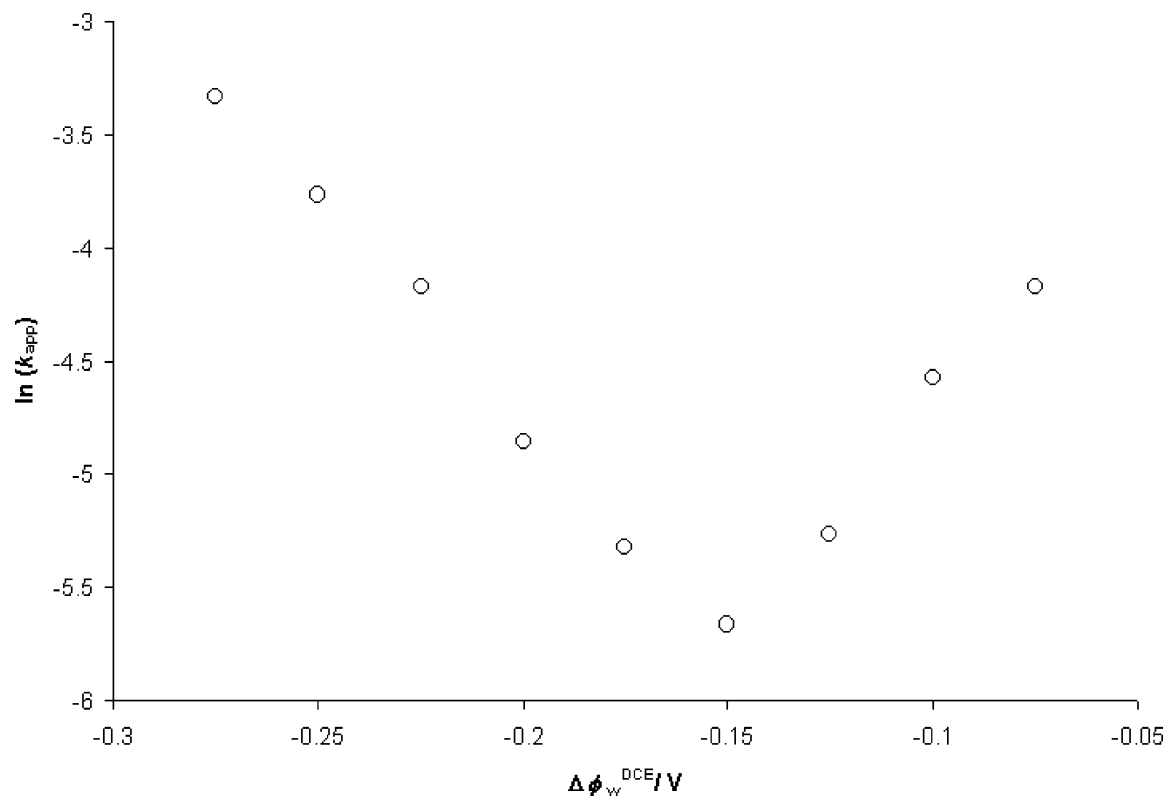

Figure 7. Dependence of the logarithm of the apparent values of the standard ion transfer constants of $\mathrm{AcH} \mathrm{H}^{+} \ln \left(k_{\text {app }}\right)$ on the applied potential difference across the water|DCE interface. $c\left(\mathrm{AcH}^{+}\right)=0.2 \mathrm{mM}$ in both water and DCE. 


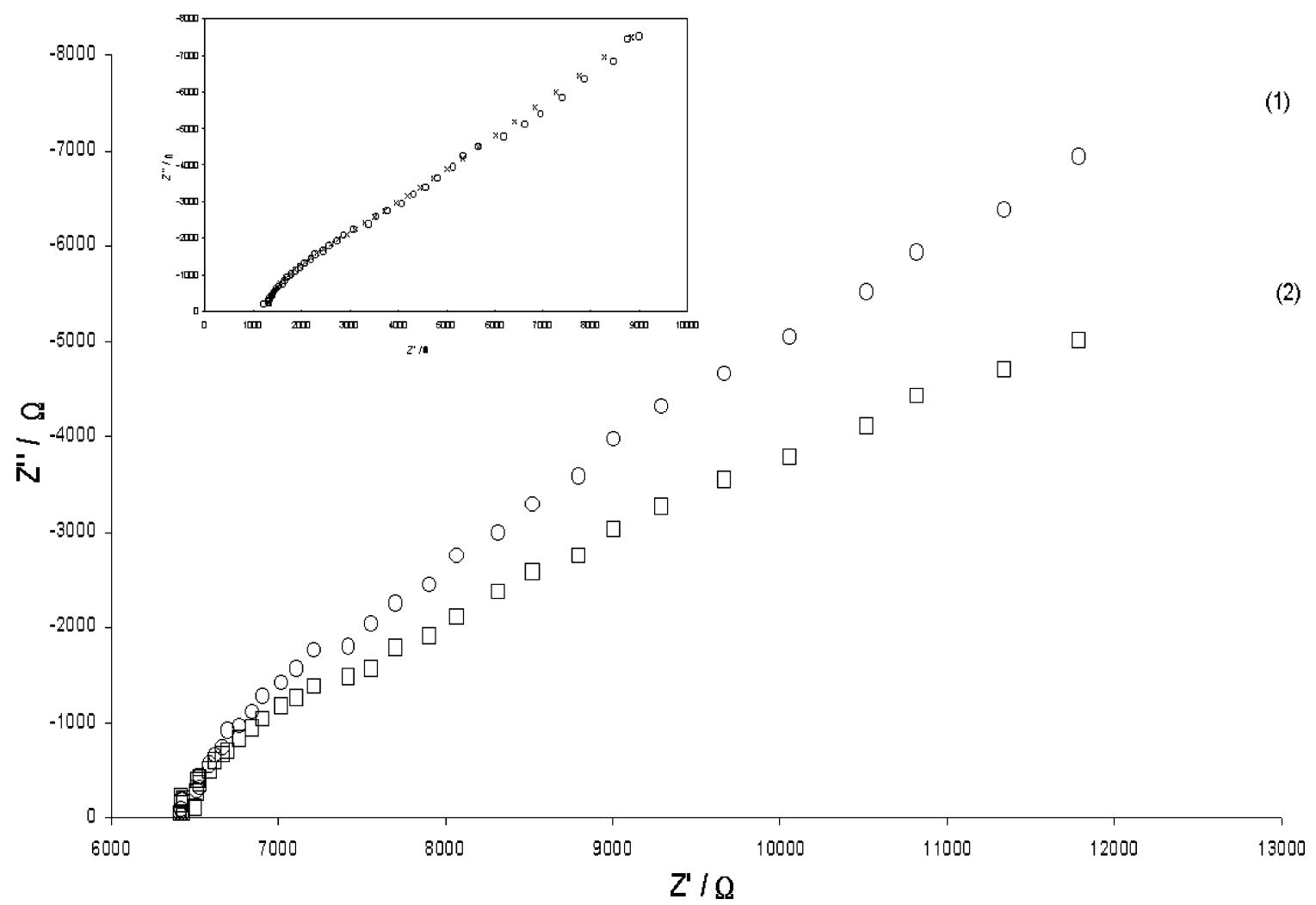

Figure 8. Nyquist impedance plots of $\mathrm{AcH}^{+}$ion transfer recorded at equilibrium potential in the absence (curve 1) and presence (curve 2) of 30 $\mu \mathrm{M}$ DOPC. $c\left(\mathrm{AcH}^{+}\right)=0.2 \mathrm{mM}$ in both water and DCE. In the inset is shown the fitting between the experimental data recorded in the presence of DOPC and theoretical data obtained by considering the Rundles equivalent circuit.

corresponds with the observed voltammetric behavior of the shifting of the formal potentials of the $\mathrm{AcH}^{+}$ion transfer toward more negative potentials, when DOPC is present in the organic phase.

\section{Surface Tension Measurements}

A different insight into the interaction between the lipid and the acetylcholine ion can be given by evaluating the effect of the cation in the compression isotherm of DOPC. The compression isotherms for the DOPC at the air|water interface were recorded at $20{ }^{\circ} \mathrm{C}$ and are similar to those described in the literature. ${ }^{46 a, b}$ The interaction between DOPC and $\mathrm{AcH}^{+}$was accessed by comparing the compression isotherms at the airwater interface with those obtained at the air-acetylcholine aqueous solution. Figure 10 shows the changes observed in the collapse pressure of the DOPC isotherms when the concentration of $\mathrm{AcH}^{+}$in the subphase is varied. The decrease of the collapse pressure denotes an increasing effect of the acetylcholine cations in the structure of the lipid film. For concentrations higher than $0.1 \mathrm{mM}$, the changes in the collapse pressure seem to reach a constant value indicating a saturation effect.

\section{Determination of the Kinetics of Chemical Interactions between $\mathrm{AcH}^{+}$and DOPC from the Voltammetric and Impedance Data}

To make entire characterizations of the kinetics of the chemical interactions between the $\mathrm{AcH}^{+}$and DOPC, one can use the approach of Nicholson and Shain. ${ }^{47}$ However, we made the kinetics evaluations by fitting the experimental and theoretical voltammograms. By having in hand the values of the standard rate constant of the ion transfer $k_{\mathrm{s}}$ of $\mathrm{AcH}^{+}$across the interface with DCE, as well as the ion transfer coefficient $\alpha$, estimated for the case of the simple ion transfer of $\mathrm{AcH}^{+}$, one needs to determine the value of the equilibrium constant of the chemical reaction, $K$, and thereafter to fit the experimental and theoretical voltammograms in order to determine the values of the rate constants of the chemical reactions, $k_{\mathrm{f}}$ and $k_{\mathrm{b}}$. The slope of the linear part of the voltammetric dependence of $E_{\mathrm{p}}$ versus $\log \left[c\left(\mathrm{AcH}^{+}\right)^{0.5}\right]$ is related to the equilibrium constant $K$ as slope $=R T / F \ln [K /(1+K)]{ }^{48}$ This dependence corresponds to the theoretical dependence of the $E_{\mathrm{p}}$ versus $\log (z)$ given in ref 48 . In this way, the value of $K$ has been estimated to be $K=0.44$ \pm 0.02 .

The value of $K$ can be also estimated from the impedance data. By applying the equations of $\mathrm{Smith}^{43 \mathrm{c}}$ to the equivalent circuit used, it can be easily shown that the series faradaic resistance $R_{\mathrm{f}}$ and the capacitive reactance $1 / \omega C_{\mathrm{f}}$ for an ECrev reaction of the type

$$
\mathrm{A}+n \mathrm{e}^{-} \rightleftarrows \mathrm{B} \underset{k_{\mathrm{b}}}{\stackrel{k_{\mathrm{f}}}{\rightleftarrows}} \mathrm{C}
$$

are given by

$$
\begin{gathered}
R_{\mathrm{f}}=\frac{1}{\sqrt{\omega}}\left(\sigma_{\mathrm{A}}+\sigma_{\mathrm{B}} \frac{K}{1+K}\right)+R_{\mathrm{ct}}+\frac{\sigma_{\mathrm{B}}}{(1+K) \sqrt{\epsilon}} \\
\frac{1}{\omega C_{\mathrm{f}}}=\frac{1}{\sqrt{\omega}}\left(\sigma_{\mathrm{A}}+\sigma_{\mathrm{B}} \frac{K}{1+K}\right)+\frac{\sigma_{\mathrm{B}}}{(1+K) \sqrt{\epsilon}}
\end{gathered}
$$

where $\sigma_{\mathrm{A}}=R T / F^{2} S c_{\mathrm{A}}^{*} \sqrt{2 D_{\mathrm{A}}}, \sigma_{\mathrm{B}}=R T / F^{2} S c_{\mathrm{B}}^{*} \sqrt{2 D_{\mathrm{B}}}, \epsilon$ is the chemical parameter defined as $\epsilon=k_{\mathrm{f}}+k_{\mathrm{b}}, \omega$ is the angular frequency, and $S$ is the surface area of the liquid|liquid interface, while the meaning of the other symbols is as mentioned before. 

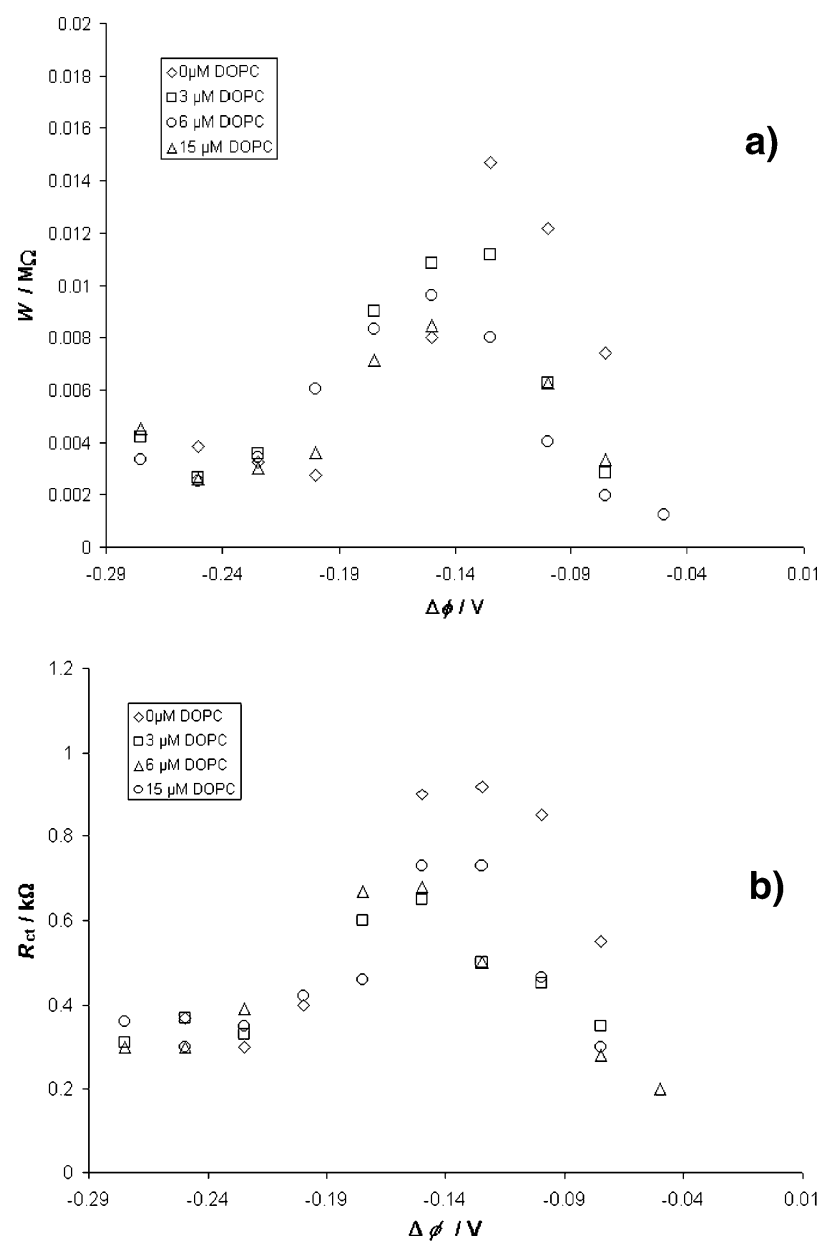

Figure 9. Effect of the concentration of DOPC to the Warburg impedance $W$ (a) and charge transfer resistance $R_{\mathrm{ct}}(\mathrm{b}) . c\left(\mathrm{AcH}^{+}\right)=0.5$ $\mathrm{mM}$ in both water and DCE.

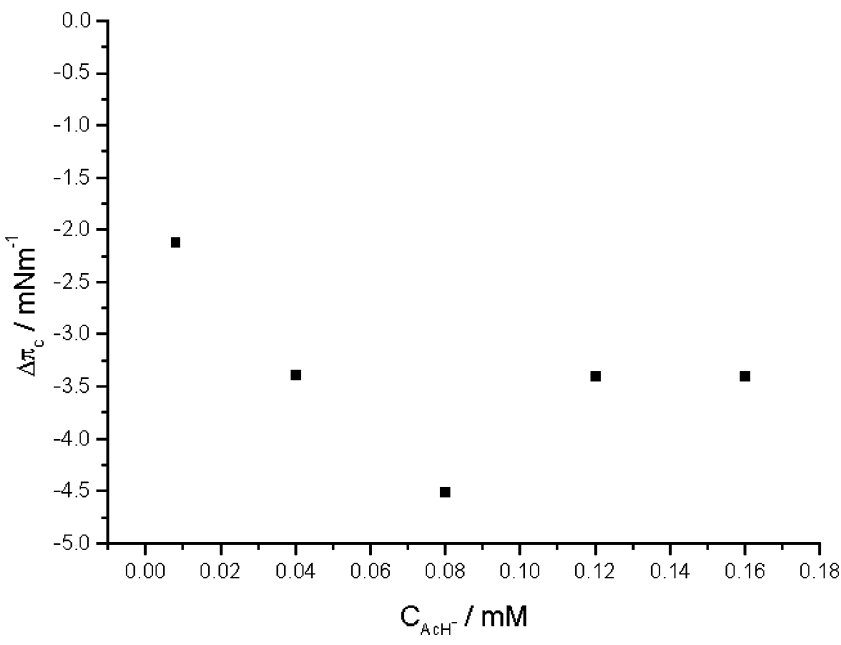

Figure 10. Effect of the concentration of $\mathrm{AcH}^{+}$on the variation of collapse pressure for the DOPC compression isotherm.

Therefore, the plot of the $R_{\mathrm{f}}$ versus $\omega^{-1 / 2}$ (or alternatively, $1 /\left(\omega C_{\mathrm{f}}\right)$ vs $\left.\omega^{-1 / 2}\right)$ for an ECrev system should be a straightforward line, with a slope defined as slope $=\sigma_{\mathrm{A}}+\sigma_{\mathrm{B}}(K / 1+K)$. Since the values of $\sigma_{\mathrm{A}}$ and $\sigma_{\mathrm{B}}$ are known from the experimental conditions, the value of $K$ can be estimated from the value of the slope of the dependence $R_{\mathrm{f}}$ versus $\omega^{-1 / 2}$. Note that the corresponding slope of $R_{\mathrm{f}}$ versus $\omega^{-1 / 2}$ dependence of a simple diffusion controlled redox reaction of type $\mathrm{A}+n \mathrm{e}^{-} \leftrightarrow \mathrm{B}$ is given by slope $=\sigma_{\mathrm{A}}+\sigma_{\mathrm{B}}$. Hence, the slope of the dependence $R_{\mathrm{f}}$ versus $\omega^{-1 / 2}$ of a redox reaction coupled with a homogeneous following chemical reaction should be smaller than the corresponding slope of a redox reaction without the chemical reaction. The corresponding dependencies of $R_{\mathrm{f}}$ versus $\omega^{-1 / 2}$ for the transfer of $\mathrm{AcH}^{+}$in the absence and presence of DOPC are presented in Figure 11. In both cases, a linear dependence of $R_{\mathrm{f}}$ on $\omega^{-1 / 2}$ has been observed, with a bigger slope when no DOPC is present in the organic phase. This finding is in complete agreement with the preceding discussion. The value of $K$ estimated from the slope of the linear line (2) of Figure 11 is found to be $K=0.80$, which is very close to the value of $K$ estimated from the voltammetric experiments. Moreover, when the value of $K$ is determined, from the intercept of the dependence shown in Figure 11, it is possible to evaluate the value of the chemical parameter $\epsilon$. The value of $\epsilon$ determined in this way has been found to be $\epsilon=13.3 \mathrm{~s}^{-1}$. Bearing in mind that $K$ and $\epsilon$ are defined as $K=k_{\mathrm{f}} / k_{\mathrm{b}}$ and $\epsilon=k_{\mathrm{f}}+k_{\mathrm{b}}$, respectively, one can determine the values of the pseudo-firstorder rate constants of the forward and backward chemical reactions between $\mathrm{AcH}^{+}$and DOPC, that is, $k_{\mathrm{f}}$ and $k_{\mathrm{b}}$. The values of $k_{\mathrm{f}}$ and $k_{\mathrm{b}}$ evaluated in this way read $k_{\mathrm{f}}=5.9 \mathrm{~s}^{-1}$ and $k_{\mathrm{b}}=7.4 \mathrm{~s}^{-1}$.

By employing a value of $K$ of 0.44 in the theoretical model, the best fitting has been obtained for values of $k_{\mathrm{f}}=4.0 \mathrm{~s}^{-1}$ and $k_{\mathrm{b}}=9.1 \mathrm{~s}^{-1}$. The corresponding comparison between the experimental SW voltammogram of $\mathrm{AcH}^{+}$ion transfer in the presence of DOPC and the theoretical voltammogram, simulated considering an ECrev reaction, is given in Figure 12. All the kinetics data, determined by SWV and EIS, are given in Table 1. It is worth noting that the small difference in the kinetic data determined from the impedance and from the voltammetric measurements can arise from the uncompensated ohmic resistance by the impedance measurements, ${ }^{51,52}$ since the ohmic drop has been compensated in the voltammetric experiments.

\section{Summary}

The transfer of acetylcholine across the biological membranes remains an exciting topic, since acetylcholine is one of the most important neurotransmitters. In order to mimic its transfer in the living cells, and to get an insight into the interactions between acetylcholine and the phospholipids, a series of electrochemical and surface tension experiments have been undertaken. The transfer of acetylcholine ions across the phospholipid-modified liquid-liquid interface is not just a simple one, but it is coupled with additional interactions with the phospholipids. The evidence of the existence of interactions between acetylcholine and the phospholipids is of fundamental significance, while it provides insight into the mechanism of ion transfer across the biological membranes. The phospholipids most probably facilitate the transfer of $\mathrm{AcH}^{+}$across the biomembranes. By employing voltammetry at the liquid|liquid interface and electrochemical impedance spectroscopy, it was possible to evaluate the kinetic parameters of the chemical interactions between the $\mathrm{AcH}^{+}$ions and the phospholipids. Though a variety of effects can play a role in the transfer of acetylcholine across the biomembranes, this study throws new light onto the function of the phospholipids by the ion transfer processes. It will be our further task to undertake molecular dynamic simulation in order to characterize at the molecular level the type and site(s) of the interactions between the acetylcholine and the phospholipids. 


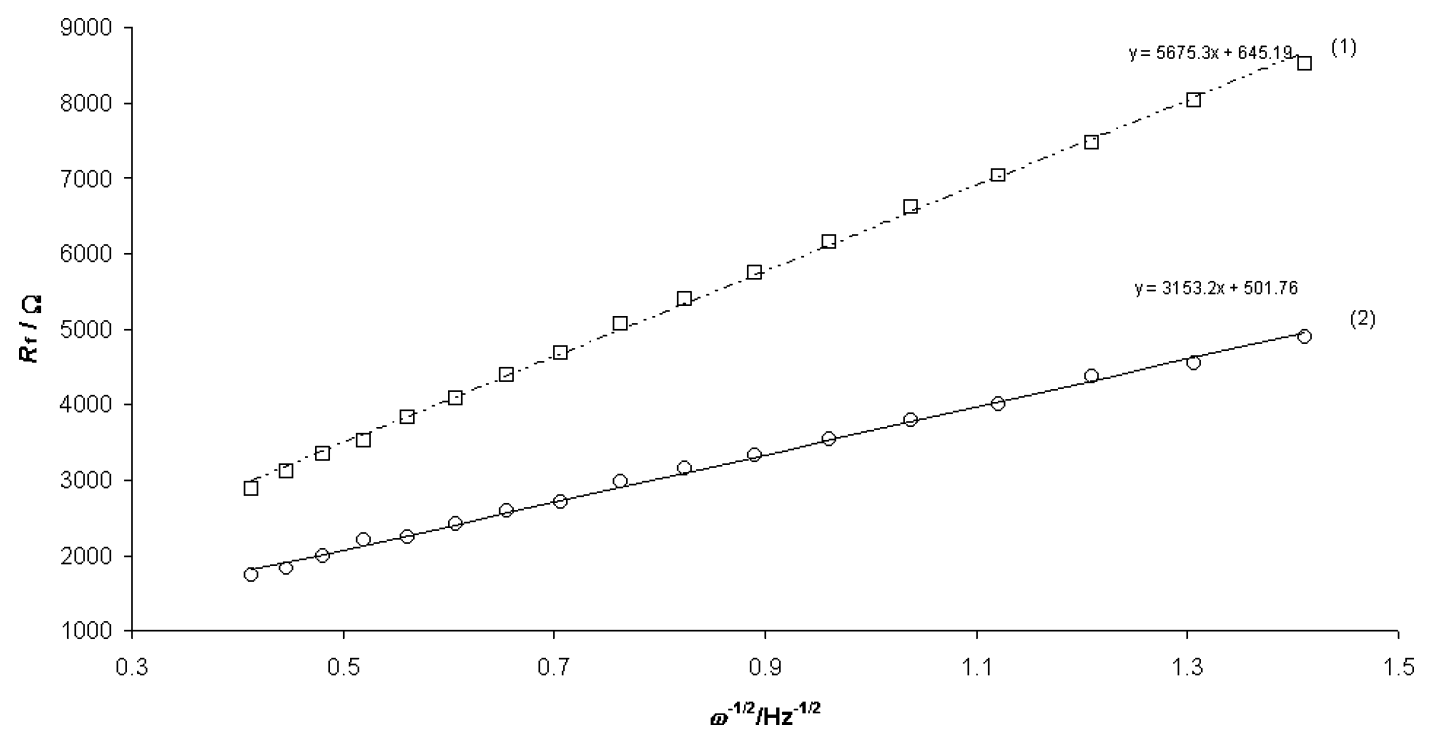

Figure 11. Dependence of the serial faradaic resistance $R_{\mathrm{f}}$ on the inverse square root of the frequency for the system without presence of DOPC (1) and with presence of $30 \mu \mathrm{M}$ DOPC in the organic phase (2). $c\left(\mathrm{AcH}^{+}\right)=0.2 \mathrm{mM}$ in both water and DCE.

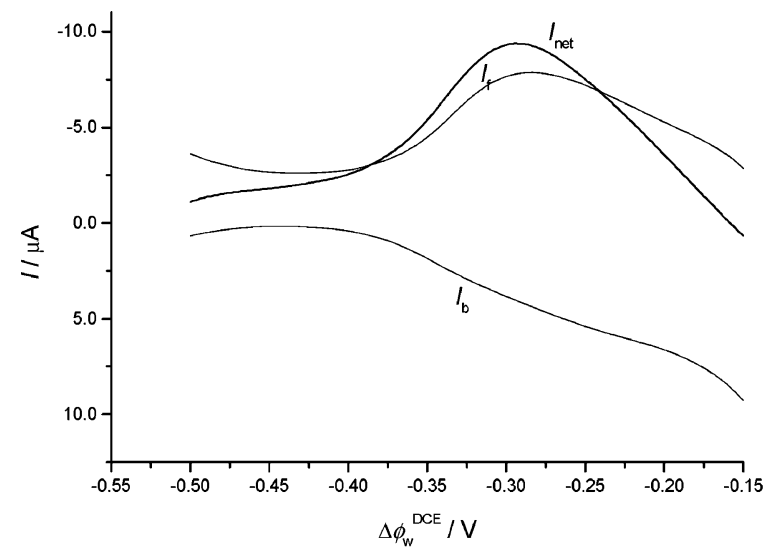

a)

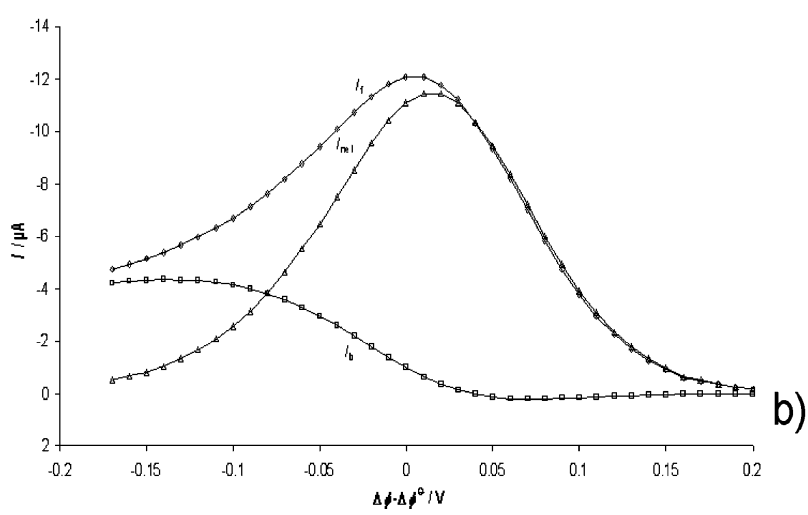

Figure 12. Comparison between the experimental SW voltammogram of the transfer of $\mathrm{AcH}^{+}$obtained in the presence of $30 \mu \mathrm{M}$ DOPC (a) and the theoretical SW voltammogram simulated by considering an ECrev reaction (b). The theoretical voltammogram is simulated under the same conditions as the experimental voltammogram (see caption of Figure $4 b^{\prime}$ ) and for the following values of the kinetic parameters: $k_{\mathrm{s}}=0.003 \mathrm{~cm} \mathrm{~s}^{-1}, K=0.44, \alpha=0.5, k_{\mathrm{f}}=4.0 \mathrm{~s}^{-1}$, and $k_{\mathrm{b}}=9.1 \mathrm{~s}^{-1}$.

\section{Appendix 1. Theoretical Model for Semi-Infinite Planar Diffusion Across Liquid|Liquid Interface}

The semi-infinite planar diffusion model for the transfer of ionic species across the liquid|liquid interface represented by the following reaction scheme

$$
\mathrm{A}^{+}(\mathrm{w}) \rightleftarrows \mathrm{A}^{+}(\mathrm{o})
$$

TABLE 1: Determined Kinetic Parameters of the Ion Transfer of $\mathrm{AcH}^{+}$from Water to DCE $\left(k_{\mathrm{s}}\right.$ and $\left.\alpha\right)$ and for the Interactions between $\mathrm{AcH}^{+}$and DOPC $\left(K, \epsilon, k_{\mathrm{f}}\right.$, and $\left.k_{\mathrm{b}}\right)$

\begin{tabular}{ccccccc}
\hline $\begin{array}{c}\text { measuring } \\
\text { technique }\end{array}$ & $k_{\mathrm{s}} / \mathrm{cm} \mathrm{s}^{-1}$ & $\alpha$ & $K$ & $\epsilon / \mathrm{s}^{-1}$ & $k_{\mathrm{f}} / \mathrm{s}^{-1}$ & $k_{\mathrm{b}} / \mathrm{s}^{-1}$ \\
\hline SWV & 0.0030 & 0.50 & 0.44 & 13.10 & 4.00 & 9.10 \\
EIS & 0.0033 & 0.53 & 0.80 & 13.30 & 5.90 & 7.40
\end{tabular}

is mathematically described with the following set of differential equations:

$$
\begin{aligned}
& \frac{\partial c_{\mathrm{A}_{(\mathrm{w})}{ }^{+}}}{\partial t}=D_{\mathrm{A}_{(\mathrm{w})}} \frac{\partial^{2} c_{\mathrm{A}_{(\mathrm{w})}}}{\partial x^{2}} \\
& \frac{\partial^{2} c_{\mathrm{A}_{(0)}{ }^{+}}}{\partial t}=D_{\mathrm{A}_{(0)}+} \frac{\partial^{2} c_{\mathrm{A}_{(0)}}{ }^{+}}{\partial x^{2}}
\end{aligned}
$$

The above differential equations are solved under the following initial and boundary conditions:

$$
\begin{gathered}
t=0, x \geq 0, c\left(\mathrm{~A}^{+}(\mathrm{w})\right)=c^{*}, c\left(\mathrm{~A}^{+}(\mathrm{o})\right)=0 \\
t>0, x \rightarrow \infty, c\left(\mathrm{~A}^{+}(\mathrm{w})\right) \rightarrow c^{*}, \mathrm{c}\left(\mathrm{A}^{+}(\mathrm{o})\right) \rightarrow 0 \\
t>0, x=0, D_{\mathrm{A}_{(\mathrm{w})}+} \frac{\partial c_{\mathrm{A}_{(\mathrm{w})^{+}}}}{\partial x}=-D_{\mathrm{A}_{(0)}+} \frac{\partial c_{\mathrm{A}_{(\mathrm{o})}}}{\partial x}=-\frac{I}{F S}
\end{gathered}
$$

where $x$ is the distance from the liquid|liquid interface, and it has a positive value toward the water and toward the organic phase. $S$ is the surface area of the liquid|liquid interface, $c^{*}$ is the initial concentration of $\mathrm{A}^{+}$in the water phase, while $D_{\mathrm{A}_{(\mathrm{w})}}{ }^{+}$ and $D_{\mathrm{A}_{(0)}}+$ are the diffusion coefficients of $\mathrm{A}^{+}$in the water and organic phases, respectively. The other symbols have their usual meanings.

It is assumed that the ion transfer across the liquid|liquid interface is partly controlled by the charge transfer rate, and therefore, the Buttler-Volmer equation is valid

$$
\frac{I}{F S}=k_{\mathrm{s}} \exp (-\alpha \varphi)\left[\left(c_{\left.\mathrm{A}_{(\mathrm{w})}+\right)_{x=0}}-\exp (\varphi)\left(c_{\mathrm{A}_{(0)}+}\right)_{x=0}\right]\right.
$$

In eq $4, k_{\mathrm{s}}\left(\mathrm{cm} \mathrm{s}^{-1}\right)$ is the standard rate constant of ion transfer of $\mathrm{A}^{+}$, while $\varphi$ is the dimensionless relative potential defined 
as $\varphi=F / R T\left(\Delta_{\mathrm{w}}^{\mathrm{o}} \varphi-\Delta_{\mathrm{w}}^{\mathrm{o}} \varphi_{\mathrm{A}^{+}}^{\theta}\right) . \Delta_{\mathrm{w}}^{\mathrm{o}} \varphi$ is the applied potential difference across the liquid|liquid interface, while $\Delta_{\mathrm{w}}^{\mathrm{o}} \varphi_{\mathrm{A}^{+}}^{\theta}$ is the standard potential of transfer of $\mathrm{A}^{+}$from water $(\mathrm{w})$ to the organic phase (o).

The solutions of eqs 1 and 2 have been obtained by means of Laplace transformations. The expressions for $c\left(\mathrm{~A}^{+}(\mathrm{w})\right)_{x=0}$ and $c\left(\mathrm{~A}^{+}(\mathrm{o})\right)_{x=0}$ are identical with those obtained by considering semi-infinite planar diffusion for a simple electrochemical reaction $\mathrm{Ox}+n \mathrm{e}^{-} \rightleftarrows$ Red and can be found elsewhere together with the numerical solutions and entire procedure describing the steps of mathematical solving and simulation manners. ${ }^{49}$ The simulations have been performed for both cyclic staircase $(\mathrm{CV})$ and square-wave (SW) voltammetry, using the MATHCAD software.

\section{Appendix 2. Theoretical Model of a Semi-Infinite Planar Diffusion Across Liquid|Liquid Interface Coupled with Following Chemical Reaction ECrev}

The mathematical model for the ion transfer across the liquid|liquid interface that is coupled by the following chemical reaction is presented by the following scheme:

$$
\mathrm{A}^{+}(\mathrm{w}) \rightleftarrows \mathrm{A}^{+}(\mathrm{o}) \underset{k_{\mathrm{b}}}{\stackrel{k_{\mathrm{f}}}{\rightleftarrows}} \mathrm{B}(\mathrm{o})
$$

In the reaction scheme (III), $k_{\mathrm{f}}\left(\mathrm{s}^{-1}\right)$ and $k_{\mathrm{b}}\left(\mathrm{s}^{-1}\right)$ are the firstorder rate constants of the forward and backward chemical reactions, respectively. In practice, the forward chemical reaction is of a pseudo-first order, undergoing as $\mathrm{A}^{+}(\mathrm{o})+\mathrm{X}(\mathrm{o}) \rightarrow \mathrm{B}(\mathrm{o})$, characterized by the second-order rate constant $k^{\prime}\left(\mathrm{mol}^{-1} \mathrm{~cm}^{3}\right.$ $\left.\mathrm{s}^{-1}\right)$. Hence, $k_{\mathrm{f}}$ is a pseudo-first-order rate constant defined as $k_{\mathrm{f}}=k_{\mathrm{f}}^{\prime} c(\mathrm{X})$. The application of the second Fick's law to any species involved in the reaction scheme (III) leads to the following differential equations:

$$
\begin{aligned}
& \frac{\partial c_{\mathrm{A}_{(\mathrm{w})}+}}{\partial t}=D_{\mathrm{A}_{(\mathrm{w})}+} \frac{\partial^{2} c_{\mathrm{A}_{(\mathrm{w})}}}{\partial x^{2}} \\
& \frac{\partial c_{\mathrm{A}_{(\mathrm{o})}{ }^{+}}}{\partial t}=D_{\mathrm{A}_{(\mathrm{o})}+} \frac{\partial^{2} c_{\mathrm{A}_{(\mathrm{o})}{ }^{+}}}{\partial x^{2}}-k_{\mathrm{f}} c_{\mathrm{A}_{(\mathrm{o})}+}+\frac{k_{\mathrm{f}}}{K} c_{\mathrm{B}(\mathrm{o})} \\
& \frac{\partial c_{\mathrm{B}(\mathrm{o})}}{\partial t}=D_{\mathrm{B}(\mathrm{o})} \frac{\partial^{2} c_{\mathrm{B}(\mathrm{o})}}{\partial x^{2}}+k_{\mathrm{f}} c_{\mathrm{A}_{(\mathrm{o})}+}-\frac{k_{\mathrm{f}}}{K} c_{\mathrm{B}(\mathrm{o})}
\end{aligned}
$$

where $K=k_{\mathrm{f}} / k_{\mathrm{b}}$ is the equilibrium constant of the following chemical reaction of reaction scheme (III). The differential eqs 5-7 have been solved under the following boundary conditions:

$$
\begin{gathered}
t=0, x \geq 0, c\left(\mathrm{~A}^{+}(\mathrm{w})\right)=c^{*}, c\left(\mathrm{~A}^{+}(\mathrm{o})\right)=c(\mathrm{~B}(\mathrm{o}))=0 \\
t>0, x \rightarrow \infty, c\left(\mathrm{~A}^{+}(\mathrm{w})\right) \rightarrow c^{*}, c\left(\mathrm{~A}^{+}(\mathrm{o})\right)=c(\mathrm{~B}(\mathrm{o})) \rightarrow 0 \\
t>0, x=0, D_{\mathrm{A}_{(\mathrm{w})}+} \frac{\partial c_{\mathrm{A}_{(\mathrm{w})}}}{\partial x}=-D_{\mathrm{A}_{(\mathrm{o})}+} \frac{\partial c_{\mathrm{A}_{(\mathrm{o})}}}{\partial x}=-\frac{I}{F S} \\
t>0, x=0, D_{\mathrm{B}(\mathrm{o})} \frac{\partial c_{\mathrm{B}(\mathrm{o})}}{\partial x}=0 \\
\frac{I}{F S}=k_{\mathrm{s}} \exp (-\alpha \varphi)\left[\left(c_{\left.\mathrm{A}_{(\mathrm{w})}+\right)_{x=0}}-\exp (\varphi)\left(c_{\mathrm{A}_{(\mathrm{o})}+}\right)_{x=0}\right]\right.
\end{gathered}
$$

The value of $\varphi$ is defined again as $\varphi=F / R T\left(\Delta_{\mathrm{w}}^{\mathrm{o}} \varphi-\Delta_{\mathrm{w}}^{\mathrm{o}}\right.$ $\left.\varphi_{\mathrm{A}^{+}}^{\theta}\right)$, while the other symbols have the usual meanings as in Appendix 1. The solutions of the differential eqs 5-7, under the relevant boundary conditions, have been obtained by using the Laplace transforms combined with the numerical integration methodology. The solutions for the concentrations of $c\left(\mathrm{~A}^{+}\right.$ (w) $)_{x=0}$ and $c\left(\mathrm{~A}^{+}(\mathrm{o})\right)_{x=0}$ are identical to those obtained for an ECrev diffusion reaction of the type

$$
\mathrm{Ox}+n \mathrm{e}^{-} \rightleftarrows \operatorname{Red} \underset{k_{\mathrm{b}}}{\stackrel{k_{\mathrm{f}}}{\rightleftarrows}} \mathrm{Y}
$$

given elsewhere. ${ }^{48,50}$ The theoretical simulation have been made for both cyclic staircase (CV) and square-wave (SW) voltammetric conditions.

Besides the temperature, ion transfer coefficient $\alpha$, and the parameters of the exciting signals in SW and CV, the voltammetric features of the considered mechanism (III) are additionally controlled from the dimensionless kinetic parameter $X$, defined as $X=k_{s} / \sqrt{D f}$ (for SW) or $X=k_{s} \sqrt{\tau} / \sqrt{D}$ (for CV) (where $f$ is the SW frequency and $\tau$ is the time of the duration of the single potential treads in the cyclic voltammetry), the equilibrium constant $K$, and a chemical parameter $z$, defined as $z=\sqrt{\epsilon} / \sqrt{f}$ (for SW) or $z=\sqrt{\epsilon \tau}$ (for CV), where $\epsilon=k_{\mathrm{f}}+k_{\mathrm{b}}$. A detailed study of the effect of all these parameters to the voltammetric features of the ECrev mechanism can be found elsewhere. ${ }^{50}$ Note that, in the experiments, the value of the chemical parameter $z$ can be varied by changing the SW frequency (or scan rate in $\mathrm{CV}$ ) or the concentration of one of the reactants of the following chemical reaction.

Acknowledgment. Rubin Gulaboski thanks Fundação para a Ciência e a Tecnologia (FCT) of Portugal for providing of a post-doctoral fellowship (SFRH/BPD/14894/2004). The authors would like to thank FCT for financial support (CIQ L4 and FEDER for the project POCTI/QUI/42472/2001).

\section{References and Notes}

(1) Volkov, A. G. In Liquid-Liquid Interfaces in Chemical, Biological and Pharmaceutical Applications; M. Dekker: New York, 2001; Vol. 95.

(2) Girault, H. H.; Schiffrin, D. J. In Electroanalytical Chemistry, A Series of Advances, Electrochemistry of Liquid-Liquid Interfaces; Bard, A. J., Ed.; M. Dekker: New York, 1989; Vol. 15; pp 1-141.

(3) Marcus, Y. Ion Properties; M. Dekker: New York, 1997.

(4) Testa, B.; van de Waterbeemd, H.; Folkers, G.; Gay, R. In Pharmacokinetic Optimization in Drug Research; Wiley-VCH: Weinheim, Germany, 2001.

(5) Hundhammer, B.; Solomon, T.; Alemu, H. J. Electroanal. Chem. 1983, 149, 179

(6) Chopineaux-Courtois, V.; Reymond, F.; Bouchard, G.; Carrupt, P.A.; Testa, B.; Girault, H. H. J. Am. Chem. Soc. 1999, 121, 1743.

(7) Gobry, V.; Ulmeanu, S. M.; Reymond, F.; Bouchard, G.; Carrupt P.-A.; Testa, B.; Girault, H. H. J. Am. Chem. Soc. 2001, 123, 10684.

(8) Wilke, S. Habilitation Thesis, Halle, 2002.

(9) Blake, A. J.; Caçote, M.; Devillanova, F. A.; Garau, A.; Isaia, F.; Lippolis, V.; Pereira, C. M.; Silva, F.; Tei, L. Eur. J. Inorg. Chem. 2002, 7, 1816.

(10) Samec, Z.; Langmaier, J.; Trojanek, A.; Samcova, E.; Malek, J. Anal. Sci. 1998, 14, 35.

(11) Wandlowski, T.; Marecek, V.; Holub, K.; Samec, Z. J. Phys. Chem. 1989, 93, 8204.

(12) Dvorak, O.; Marecek, V.; Samec, Z. J. Electroanal. Chem. 1990, 284, 205.

(13) Wandlowski, T.; Marecek, V.; Samec, Z. J. Electroanal. Chem. 1988, 242, 291.

(14) Kakiuchi, T.; Noguchi, J.; Senda, M. J. Electroanal. Chem. 1992, 327,63 .

(15) Koryta, J.; Vanysek, P.; Brezina, M. J. Electroanal. Chem. 1977, $75,211$.

(16) Koryta, J. Electrochim. Acta 1979, 24, 293

(17) Reymond, F.; Carrupt, P.-A.; Girault, H. H. J. Electroanal. Chem. 1998, $449,49$.

(18) Reymond, F.; Brevet, P. F.; Carrupt, P.-A.; Girault, H. H. J. Electroanal. Chem. 1997, 424, 121.

(19) Reymond, F.; Steyaert, G.; Carrupt, P.-A.; Testa, B.; Girault, H. J. Am. Chem. Soc. 1996, 118, 11951. 
(20) Kakiuchi, T. Anal. Chem. 1996, 68, 3658.

(21) Cheng, Y.; Schiffrin, D. J. Chem. Soc., Faraday Trans. 1993, 89, 199.

(22) Stewart, A. A.; Campbell, J. A.; Girault, H. H. Ber. Bunsen-Ges. Phys. Chem. 1990, 94, 83.

(23) Gulaboski, R.; Mirčeski, V.; Scholz, F. Electrochem. Commun. 2002, 4, 277.

(24) Gulaboski, R.; Galland, A.; Bouchard, G.; Caban, K.; Kretschmer, A.; Carrupt, P.-A.; Stojek, Z.; Girault, H. H.; Scholz, F. J. Phys. Chem. B 2004, 108, 4565.

(25) Gulaboski, R.; Scholz, F. J. Phys, Chem. B 2003, 107, 5650.

(26) Scholz, F.; Komorsky-Lovrič, Š.; Lovrič, M. Electrochem. Commun. 2000, 2, 112 .

(27) Scholz, F.; Schröder, U.; Gulaboski, R. In Electrochemistry of Immobilized Particles and Droplets; Springer Verlag: Berlin, 2005.

(28) Scholz, F.; Gulaboski, R. ChemPhysChem 2005, 6, 16.

(29) Mirčeski, V.; Gulaboski, R.; Scholz, F. Electrochem. Commun. 2002, 4, 813 .

(30) Mirčeski, V.; Gulaboski, R.; Scholz, F. J. Electroanal. Chem. 2004, 566,351 .

(31) Figaszewski, Z.; Paleska, I. J. Electroanal. Chem. 1989, 266, 253.

(32) Rueda, M.; Navarro, I.; Prado, C.; Silva, C. J. Electrochem. Soc. 2001, 148, E139.

(33) Samec, Z.; Trojanek, A.; Girault, H. H. Electrochem. Commun. 2003, 5, 98 .

(34) (a) Yudi, L. M.; Santos, E.; Baruzzi, A. M.; Solis, V. M. J. Electroanal. Chem. 1994, 379, 151. (b) Wilke, N.; Baruzzi, A. M. J. Electroanal. Chem. 2002, 537, 67.

(35) (a) Wandlowski, T.; Marecek, V.; Samec, Z. J. Electroanal. Chem 1988, 242, 291. (b) Wandlowski, T.; Racinsky, S.; Marecek, V.; Samec, Z. J. Electroanal. Chem. 1987, 227, 281. (c) Samec, Z.; Lhotsky, A.; Janchenovana, H.; Marecek, V. J. Electroanal. Chem. 2000, 483, 47. (d) Maeda, K.; Janchenova, H.; Lhotsky, A.; Stibor, I.; Budka, J.; Marecek,

V. J. Electroanal. Chem. 2001, 516, 103.

(36) Vanysek, P.; Behrendt, M. J. Electroanal. Chem. 1981, 130, 287.

(37) Samec, Z.; Marecek, V.; Homolka, D. J. Electroanal. Chem. 1983 $158,25$.

(38) Shao. Y.; Girault, H. H. J. Electroanal. Chem. 1990, 282, 59.

(39) Pereira, C. M.; Silva, F.; Sousa, M. J.; Kontturi, K.; Murtomäki,

L. J. Electroanal. Chem. 2001, 509, 148.

(40) Kong, Y.-T.; Imabayashi, S.; Kakiuchi, T. J. Am. Chem. Soc. 2000 , 122,8215 .

(41) Fernandez, M. A.; Yudi, L. M.; Baruzzi, A. M. Electroanalysis 2004, 16, 491

(42) Canas, P.; Lorenzo, M. S.; Duo, R.; Celdran, R. Z. Phys. Chem. (Leipzig) 1990, 271, 847.

(43) (a) Sluyters-Rehbach, M.; Sluyters, J. H. J. Electroanal. Chem. 1969, 23, 457. (b) Sluyters-Rehbach, M.; Sluyters, J. H. J. Electroanal. Chem. 1970, 26, 237. (c) Smith, D. E. Anal. Chem. 1963, 35, 602.

(44) Prieto, F.; Rueda, M.; Navarro, I.; Sluyters-Rehbach, M.; Sluyters,

J. H. J. Electroanal. Chem. 1996, 405, 1.

(45) Bongenaar, C. P. M.; Remijnse, A. G.; Sluyters-Rehbach, M.; Sluyters, J. H. J. Electroanal. Chem. 1980, 111, 139.

(46) (a) Yuan, C.; Furlong, J.; Burgos, P.; Johnstn, L. J. Biophyis. J. 2002, 82, 2526. (b) Van Mau, N.; Vié, V.; Chaloin, L.; Lesniewska, E.; Heitz, F.; Le Grimellec, C. J. Membr. Biol. 1999, 167, 241

(47) Nicholson, R. S.; Shain, I. Anal. Chem. 1964, 36, 706.

(48) Osteryoung, J.; O’Dea, J. J. In Electroanalytical Chemistry, A Series of Advances; Bard, A. J., Ed.; M. Dekker: New York, 1986; Vol. 14.

(49) Mirèeski, V.; Gulaboski, R.; Kuzmanovski, I. Bull. Chem. Technol. Maced. 1999, 18, 57.

(50) Garay, F.; Lovrič, M. J. Electroanal. Chem. 2002, 518, 91.

(51) Mirčeski, V.; Lovrič, M. J. Electroanal. Chem. 2001, 497, 114.

(52) Juarez, A. V.; Baruzzi, A. M.; Yudi, L. M. J. Electroanal. Chem. In press. 